www.nature.com/hr

\title{
The role of blood pressure variability in misdiagnosed clinic hypertension
}

\begin{abstract}
Amos Cahan ${ }^{1}$, Iddo Z Ben-Dov², Judith Mekler ${ }^{1}$ and Michael Bursztyn ${ }^{1}$
Blood pressure (BP) assessment may be vulnerable to bias by increased BP variability. Uncertainty in determining BP control is inherent to the clinic setting. We analyzed a registry of 3949 patients referred for ambulatory BP monitoring. The difference between clinic and ambulatory readings was plotted against ambulatory BP variability, assessed by standard deviation. In addition, BP variability of patients with clinic and awake ambulatory hypertension was compared with that of patients with controlled BP and sustained hypertension, respectively. The average clinic-ambulatory systolic BP difference was $5 \pm 17 / 3 \pm 9 \mathrm{~mm} \mathrm{Hg}$. Patients with $>10-\mathrm{mm} \mathrm{Hg}$ systolic difference had higher systolic ambulatory BP standard deviation $(14.9 \pm 4.2 \mathrm{~mm} \mathrm{Hg}$ ) compared to patients with a difference of 0 to $10-\mathrm{mm} \mathrm{Hg}$ (standard deviation $12.5 \pm 3.7 \mathrm{~mm} \mathrm{Hg}$ ). Patients with masking (negative clinic-ambulatory BP difference) also had comparatively higher standard deviation $(14.4 \pm 4.9 \mathrm{~mm} \mathrm{Hg}$ $\boldsymbol{P}<0.0001$ ). Greater ambulatory BP variability carried increased risk for both false diagnosis of hypertension (odds ratio (OR): $2.09,95 \%$ confidence interval (CI): $1.58-2.76$ ), and missed clinic diagnosis of hypertension (OR: $1.86,95 \%$ confidence interval: 1.48-2.33). The former was more striking in women, in whom high variability carried greater odds for false diagnosis of hypertension (OR: 2.76, 95\% confidence interval: 1.96-3.89). Thus, clinic misjudgment of BP control may stem in part from high BP variability. Women with high BP variability are more susceptible to hypertension misdiagnosis. It is possible that high $\mathrm{BP}$ variability contributes to the increased cardiovascular risk related to both masked hypertension and white coat hypertension. Hypertension Research (2011) 34, 187-192; doi:10.1038/hr.2010.190; published online 11 November 2010
\end{abstract}

Keywords: blood pressure variability; gender differences; masked hypertension; white coat hypertension

\section{INTRODUCTION}

Patients with white coat hypertension (WCH), also referred to as having 'isolated clinic hypertension', have higher than normal clinic blood pressure (BP) with normal home BP readings or ambulatory $\mathrm{BP}$ monitoring (ABPM). This phenomenon, shown to increase in prevalence with age, ${ }^{1}$ may be confined to the clinic setting as recently reported. ${ }^{2}$ However, it may reflect a generalized tendency to raise BP intermittently (for example, as an enhanced stress response), both in clinic and in normal daily life. It has been shown, for example, that the fraction of patients in an outpatient clinic who had isolated ambulatory hypertension (normal in-clinic readings with abnormally high ABPM), namely masked hypertension ( $\mathrm{MH})$, declined with repeated clinic BP measurements. ${ }^{3}$ The question whether the white coat and masking phenomena are linked with increased BP variability remains to be answered; ${ }^{4}$ considerable data links increased BP variability to worse prognosis in patients with elevated BP or controlled hypertension, ${ }^{5-10}$ whereas several studies suggest that prognosis of patients with $\mathrm{WCH}$ and $\mathrm{MH}$ is worse than that of subjects with 'truly' normal BP. ${ }^{11-13}$ Recently, both $\mathrm{WCH}$ and $\mathrm{MH}$ have been shown to predict sustained hypertension in subsequent ambulatory monitoring. ${ }^{14}$
Our hypothesis in this study was that large differences between clinic and ambulatory BP, found among patients with both MH and $\mathrm{WCH}$, can be associated with increased ambulatory BP variability. In addition, we aimed to quantify the risk of inaccurate assessment of BP control in the clinic (under- or overestimation) in patients with high BP variability.

\section{METHODS}

Study population

Data were extracted from records consecutively collected in our ABPM service database, from 1991 through 2005. Both treated and non-treated patients were included, except those $<16$ years old, pregnant women and subjects with poor quality ABPM ( $<50$ valid measurements). Patients were referred for standard clinical indications at the discretion of the referring physician (mainly by primary care practitioners, who have been shown to use ABPM for appropriate indications). ${ }^{15}$

\section{$\mathrm{ABPM}$ and definitions}

The 24-hour ABPM was executed with Spacelabs 90207 (Spacelabs Healthcare, Issaquah, WA, USA). Before 1999, we used Accutracker II (SunTech Medical Inc., Morrisville, NC, USA), as previously described. ${ }^{16}$ The Accutracker II has been validated by intraarterial BP monitoring during exercise and at rest. ${ }^{17,18}$

\footnotetext{
${ }^{1}$ Hypertension Unit, Department of Medicine, Hadassah-Hebrew University Medical Center, Jerusalem, Israel and ${ }^{2}$ Laboratory of RNA Molecular Biology, The Rockefeller University, New York, NY, USA

Correspondence: Dr A Cahan, Hypertension Unit, Department of Medicine, Hadassah-Hebrew University Medical center, Mount Scopus, PO Box 24035, Jerusalem 91240, Israel.

E-mail: amoscahan@yahoo.com

Received 29 December 2009; revised 1 June 2010; accepted 30 July 2010; published online 11 November 2010
} 
The monitor was mounted on the nondominant arm between 0800 hours and 1000 hours and removed 24 hours later. Recordings were made every $20 \mathrm{~min}$ between 0600 hours and midnight and every 30 min between midnight and 0600 hours. A mercury sphygmomanometer was initially attached to the monitor via a Y-connector to verify agreement between the two modes of measurement (within a range of $5 \mathrm{~mm} \mathrm{Hg}$ ). Cuff size was selected according to measured arm circumference: $\leqslant 24-\mathrm{cm}$ pediatric cuff, $24-$ to $32-\mathrm{cm}$ standard adult cuff and $>32-\mathrm{cm}$ large adult cuff. The average of two to three initial clinic (sphygmomanometer) measurements, taken by a trained technician after the subject had been in a sitting position for $5 \mathrm{~min}$, was considered the patient's clinic BP. ${ }^{19}$ Clinic BP was considered optimal, high normal or high at $<130 / 80 \mathrm{~mm} \mathrm{Hg}$, $130-139 / 80-89 \mathrm{~mm} \mathrm{Hg}$ and $140 / 90 \mathrm{~mm} \mathrm{Hg}$, respectively. Clinic hypertension was further classified as grade I ( $<160 / 100 \mathrm{~mm} \mathrm{Hg})$, grade II $(<180 / 110 \mathrm{~mm} \mathrm{Hg})$ or grade III $(180 / 110 \mathrm{~mm} \mathrm{Hg}$ or higher). Ambulatory awake BP was considered normal or high at $<135 / 85 \mathrm{~mm} \mathrm{Hg}$ or $135 / 85$, respectively. Sleep, including daytime naps (reported in $31 \%$ ), was logged in a diary. Daytime sleep was not included in the awake BP average. Normal sleep BP was considered $<120 / 70 \mathrm{~mm} \mathrm{Hg} .^{20,21}$ The overall 24-h normality definition was $<125 /$ $80 \mathrm{~mm} \mathrm{Hg}{ }^{22}$ On the basis of combined clinic and awake ambulatory BP (aABP) readings, patients were classified as having controlled BP (normal clinic and awake BP; namely, both normotensives and controlled hypertension), or as having clinic hypertension (high clinic BP with normal awake $\mathrm{BP}$; either WCH or white coat uncontrolled hypertension), aABP hypertension (high awake BP with normal clinic BP in patients with $\mathrm{MH}$ or masked uncontrolled hypertension) or sustained hypertension (both high clinic and high awake ambulatory BP). For each patient, we subtracted the awake systolic ambulatory $\mathrm{BP}(\mathrm{aABP})$ from the clinic systolic $\mathrm{BP}$ to define the clinic-aABP difference, a measure of discrepancy between the two settings and a proxy measure of the white coat and masking phenomena. ${ }^{19}$ Variability of aABP was estimated using standard deviation (s.d.) and the coefficient of variation $\left(\mathrm{CV}=100^{\star}\right.$ s.d./average $\left.\mathrm{aABP}\right)$

\section{Data analyses}

To characterize the association between the clinic-aABP difference and the variability of ambulatory systolic $\mathrm{BP}$, the study population was split according to predetermined clinic-aABP difference cutoffs: between 0 and $-10 \mathrm{~mm} \mathrm{Hg}$ (masking), $<-10 \mathrm{mmHg}$ (extreme masking) between 0 and $10 \mathrm{~mm} \mathrm{Hg}$ (neutral difference) and $>10 \mathrm{~mm} \mathrm{Hg}$ (white coat effect (WCE)). Baseline characteristics including treatment for hypertension were compared across these categories. We further categorized the study population according to tertiles of awake systolic BP variability $(\mathrm{CV})$. We used a logistic regression model to examine the odds of $\mathrm{WCH}$ and $\mathrm{MH}$ according to aABP variability. The models also included variables for age, gender, treated hypertension and diabetes, body mass index, systolic aABP and a dummy variable for the BP monitor—Spacelab 90207 or Accutracker II. The interaction term monitor*BP variability was introduced when significant. We also examined the interaction of ambulatory BP and gender with the appropriate multiplicative term. General linear models were used to estimate covariate-adjusted ambulatory BP variability. Data are expressed as mean \pm s.d., unless otherwise specified. Two-sided nominal $P<0.05$ was considered significant. PASW Statistics 17.0 (SPSS, Chicago, IL, USA) was used for statistical analysis.

\section{RESULTS}

During a 15-year period, 3949 patients aged 16-93 years underwent valid ambulatory monitoring in our service. The study population characteristics are shown in Table 1 . In all, $58 \%$ of the patients had treated hypertension. Average clinic BP and aABP were $147 \pm 22$ / $85 \pm 13 \mathrm{~mm} \mathrm{Hg}$ and $142 \pm 16 / 82 \pm 11 \mathrm{~mm} \mathrm{Hg}$, respectively. The average difference between clinic $\mathrm{BP}$ and $\mathrm{aABP}$ was $5 \pm 17 / 3 \pm 9 \mathrm{~mm} \mathrm{Hg}$.

\section{Systolic BP variability and the clinic-ambulatory difference}

Awake ambulatory systolic BP variability was higher in patients with large differences between the clinic and aABP, both positive and negative (Table 1$)$. Patients with a positive $(>10 \mathrm{~mm} \mathrm{Hg})$ clinicaABP difference (that is, WCE) had higher unadjusted systolic BP variability (s.d. $15 \pm 4 \mathrm{~mm} \mathrm{Hg}, \mathrm{CV} 10.5 \pm 2.8 \%$ ) compared with patients with a difference of $0-10 \mathrm{~mm} \mathrm{Hg}$ (s.d. $12 \pm 4 \mathrm{~mm} \mathrm{Hg}, \mathrm{CV}$ $8.9 \pm 2.5 \%$ ). Patients with a marked negative difference (beyond $10 \mathrm{~mm} \mathrm{Hg}$ ) also had high systolic BP variability (s.d. $17 \pm 5 \mathrm{~mm} \mathrm{Hg}$, CV $11.1 \pm 3.3 \%)$ compared with those with moderate negative difference $(-10-0 \mathrm{~mm} \mathrm{Hg}$; s.d. $13 \pm 4 \mathrm{~mm} \mathrm{Hg}$, CV $9.2 \pm 2.9 \%$, both Bonferroni-corrected $P$-values $<0.0001)$. In a parallel analysis by deciles of the clinic-awake ambulatory difference a similar pattern was found in treated and non-treated patients (Figure 1). Accordingly, compared with patients with controlled BP and sustained hypertensive subjects, patients with clinic hypertension and hypertension according to aABP had higher systolic aABP variability (Figure 2).

A similar pattern was noted when $24 \mathrm{~h}$ systolic BP variability was compared across categories of clinic-ABP difference (Figure 3); Patients with a large positive or negative difference had higher

Table 1 Demographic characteristics of the study population split according to the magnitude of the clinic-awake ambulatory systolic blood pressure difference $(n=3949)$

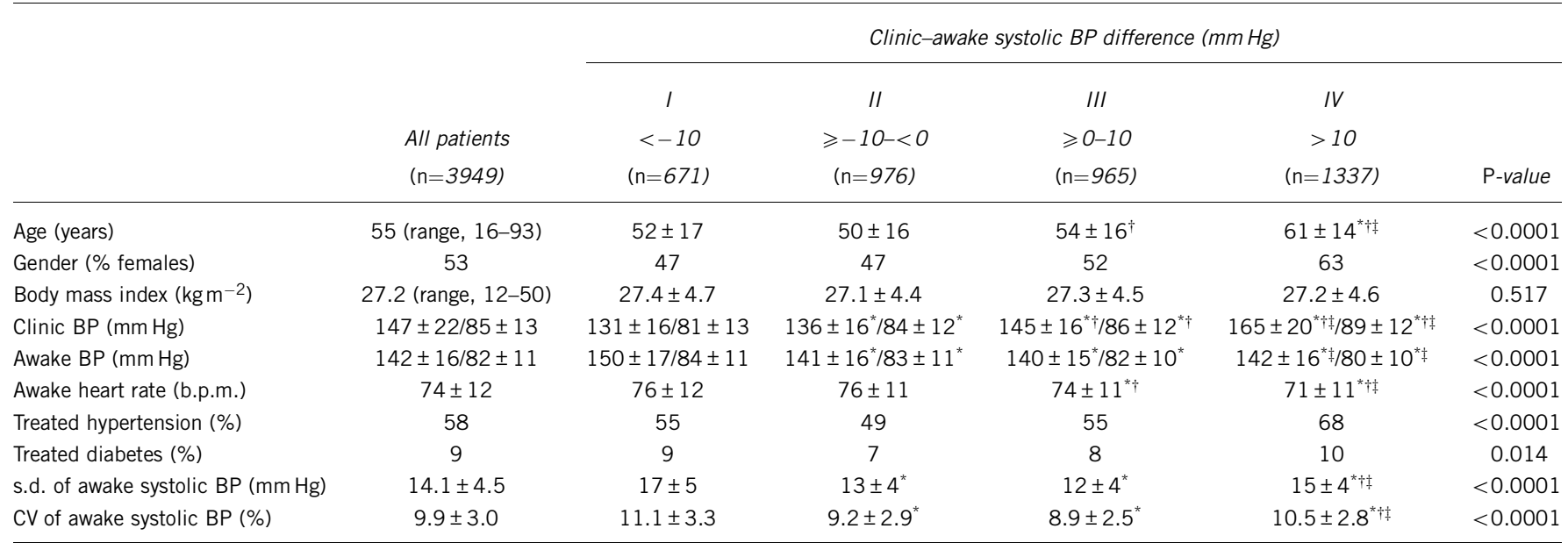

Abbreviations: BP, blood pressure; b.p.m., beats per minute; $\mathrm{CV}$, coefficient of variation.

$P$-values were derived from analysis of variance or $\chi^{2}$ tests, as appropriate. Bonferroni adjustment for multiple comparisons: ${ }^{*} P<0.05$ vs. group I; ${ }^{\dagger} P<0.05$ vs. group II; ${ }^{\ddagger} P<0.05$ vs. group III. 


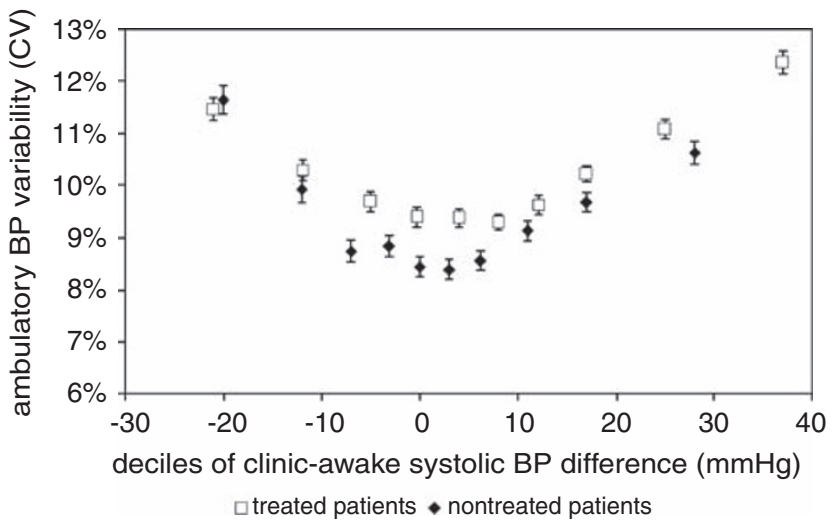

Figure 1 Unadjusted systolic aABP variability according to deciles of systolic clinic-aABP difference in nontreated (black diamonds) and treated patients (open squares). The $R^{2}$ values for the quadratic fit-lines (not shown) were 0.916 (non-treated patients) and 0.964 (treated patients). aABP, awake ambulatory blood pressure; BP, blood pressure; CV, coefficient of variation.

variability than patients with a difference $<10 \mathrm{~mm} \mathrm{Hg}(15.1 \pm 3.7$, $14.3 \pm 4.9$ and $12.4 \pm 3.3 \mathrm{~mm} \mathrm{Hg}$, respectively). Differences were significant after Bonferroni correction $(P<0.0001)$. Patients receiving antihypertensive treatment had a clinic-ABP difference similar to that of untreated patients (Figure 3).

Age- and gender-adjusted systolic aABP variability was virtually the same in diabetics and non-diabetics (s.d. $14.0 \mathrm{~mm} \mathrm{Hg}$, standard error $0.1 \mathrm{~mm} \mathrm{Hg}$ and s.d. $14.1 \mathrm{~mm} \mathrm{Hg}$, standard error $0.2 \mathrm{~mm} \mathrm{Hg}$, respectively).

\section{Systolic BP variability and the clinic-ambulatory difference in patients with normal $v s$. high ambulatory $\mathrm{BP}$}

In models computing BP variability according to the systolic clinicawake ambulatory difference, a significant interaction was noted with awake ambulatory BP. Thus, determinations of the link between systolic BP variability and the clinic-ambulatory BP discrepancy were conducted separately in patients with normal $(<135 /$ $85 \mathrm{~mm} \mathrm{Hg}$ ) or high awake ambulatory BP. In Figure 4, a mirror image shows that systolic BP variability increases with the degree of clinic hypertension in patients with normal ambulatory BP, whereas the opposite is true in patients with ambulatory hypertension.

As we hypothesized, increased systolic BP variability was involved with inaccurate clinic diagnosis of BP control in patients with both normal and high ambulatory measurements. In patients with normal awake BP, having ambulatory systolic BP variability in the upper tertile (vs. lower two tertiles) conferred odds ratio (OR) of $1.63(95 \%$ confidence interval (CI) 1.26-2.11) toward a false-positive diagnosis of hypertension according to clinic measurement, after adjustment for age (exponential term), gender, body mass index and treatment status for hypertension and diabetes. Conversely, in patients with high awake $\mathrm{BP}$, having ambulatory systolic BP variability in the upper tertile associated with OR of 1.86 (95\% CI 1.52-2.28) toward a false-negative diagnosis of normal BP in the clinic. With $\mathrm{CV}$ of awake systolic BP as a continuous variable, the results for $\mathrm{WCH}$ were blunted (Table 2). Nonetheless, in view of the fact that women are more susceptible to $\mathrm{WCH}$, we reanalyzed data according to gender (Table 3). Among subjects of both sexes with high clinic BP, higher variability predisposed to aABP hypertension (not shown). However, there was a gender-dependent relationship between variability and clinic

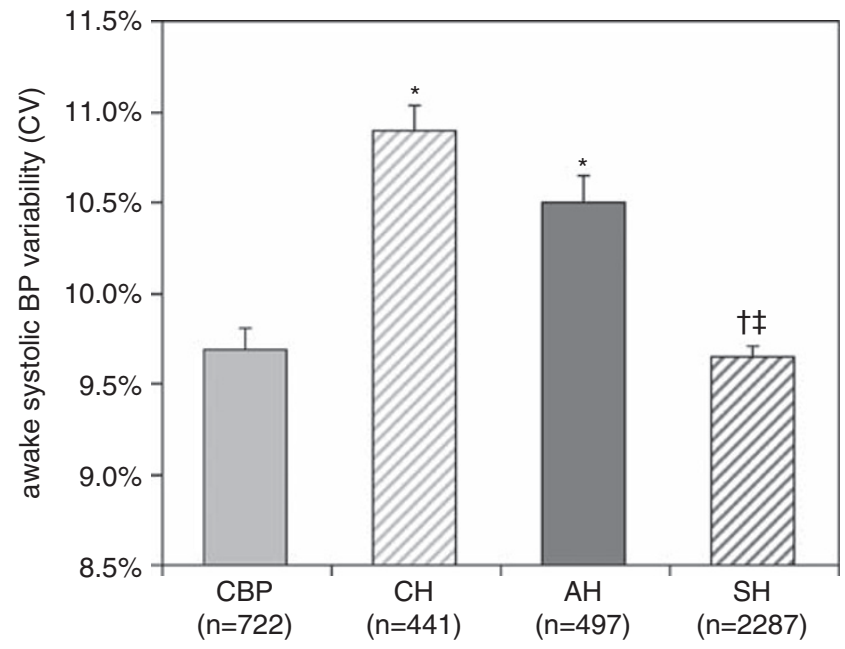

Figure 2 Unadjusted awake systolic blood pressure (BP) variability by BP categories. Controlled BP (CBP), clinic hypertension $(\mathrm{CH})$, awake hypertension $(\mathrm{AH})$ and sustained hypertension $(\mathrm{SH})$. Overall $P$-value (analysis of variance) $<0.0001$. In post hoc analyses (Bonferroni); ${ }^{*} P<0.0001$ for the comparison with $\mathrm{CBP} ;{ }^{\dagger} P<0.0001$ for the comparison with $\mathrm{CH} ;{ }^{\ddagger} P<0.0001$ for the comparison with $\mathrm{AH}$.

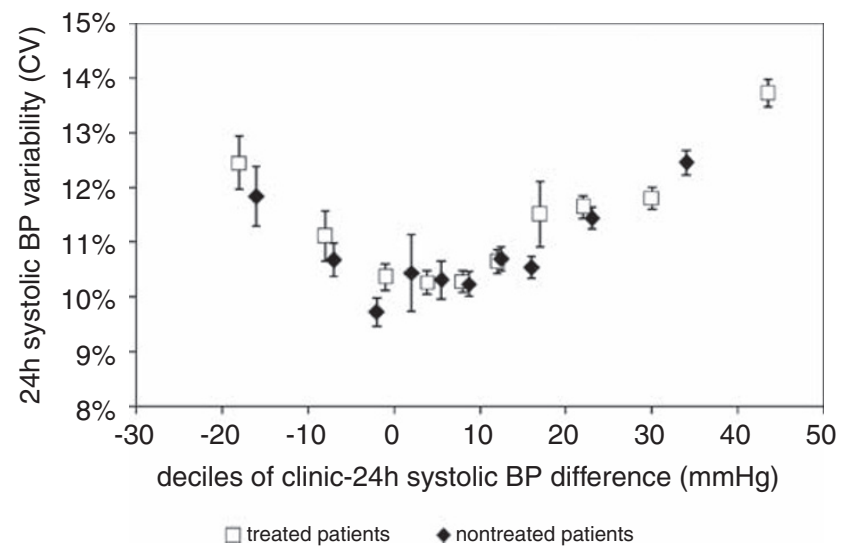

Figure 3 Unadjusted systolic $24 \mathrm{~h}$ ambulatory blood pressure (BP) variability according to deciles of systolic clinic-24 $\mathrm{h}$ ambulatory BP difference in nontreated (black diamonds) and treated patients (open squares). CV, coefficient of variation.

hypertension (interaction $P$-value $<0.05$ ). Women with normal ambulatory BP and high (third tertile) variability had a markedly increased risk of being falsely diagnosed with hypertension compared to women with less variable BP (OR: 2.36, 95\% CI 1.67-3.34). On the other hand, in men with normal ambulatory BP, high systolic BP variability was not associated with an increased risk of clinic hypertension (OR: 0.98, 95\% CI 0.58-1.64).

\section{DISCUSSION}

Our results indicate that patients with $\mathrm{WCH}$ or $\mathrm{MH}$, as well as white coat uncontrolled hypertension or masked uncontrolled hypertension, have increased daytime systolic BP variability which is not confined to the clinic setting. This higher systolic BP variability may reflect an enhanced stress response to external stimuli, and not isolated clinic reaction. Alternatively, these patients' high systolic BP variability may be intrinsic. It should be noted, however, that the clinic-aABP 


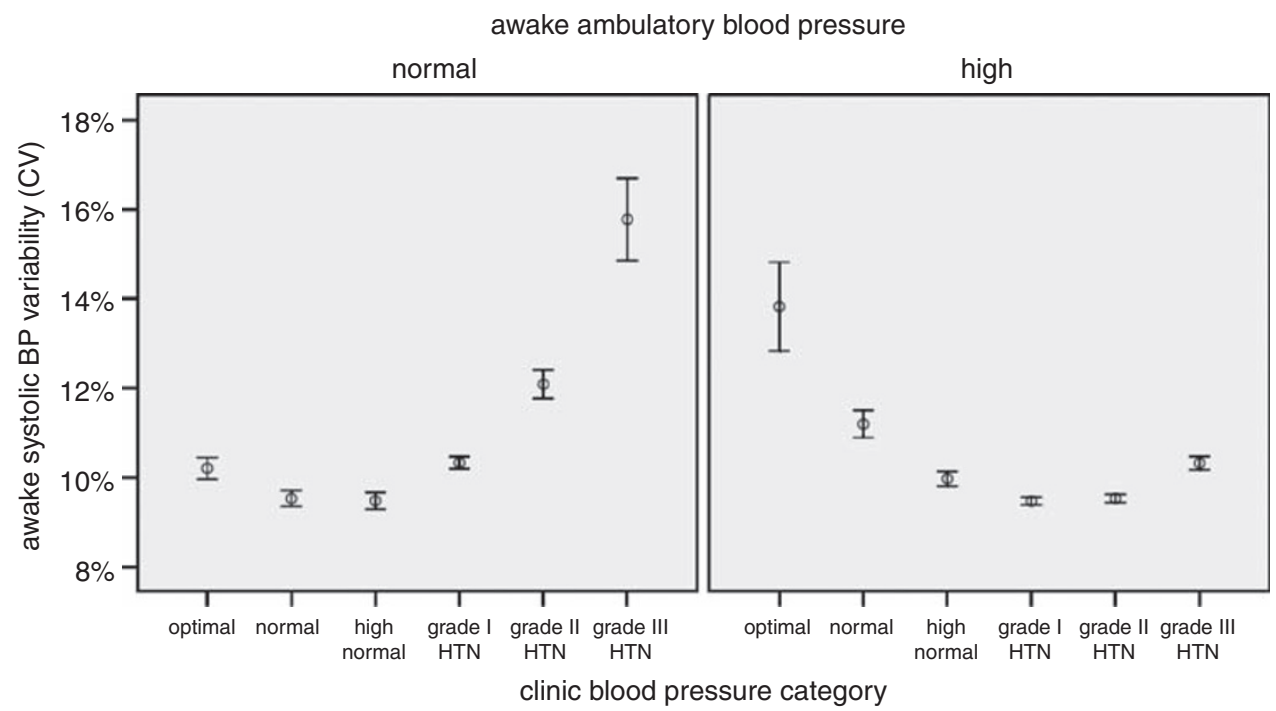

Figure 4 Unadjusted awake systolic ambulatory blood pressure (BP) variability in patients with normal $(<135 / 85 \mathrm{~mm} \mathrm{Hg}$, left panel) or high ( $\geqslant 135 /$ $85 \mathrm{~mm} \mathrm{Hg}$, right panel) awake BP by clinic BP categories: optimal <120/80 mm Hg; normal <130/85 mm Hg; high normal <140/90 mm Hg; grade I HTN $<160 / 100 \mathrm{~mm} \mathrm{Hg}$; grade II HTN <180/110 mm Hg; grade III HTN $\geqslant 180 / 110 \mathrm{~mm} \mathrm{Hg}$. CV, coefficient of variation; HTN, hypertension.

Table 2 Clinical predictors of misdiagnosed blood pressure status by categories of ambulatory blood pressure

\begin{tabular}{|c|c|c|c|c|c|}
\hline Predictor & Unit & OR for $W C H$ & P-value & OR for $M H$ & P-value \\
\hline Age & 5 Years & $1.16(1.10-1.22)$ & $<0.0001$ & $0.88(0.85-0.91)$ & $<0.0001$ \\
\hline Gender & $\mathrm{F} / \mathrm{M}$ & $1.30(0.97-1.73)$ & 0.074 & $0.83(0.67-1.03)$ & 0.086 \\
\hline Treated hypertension & Yes/no & $0.96(0.70-1.31)$ & 0.798 & $1.09(0.86-1.39)$ & 0.454 \\
\hline Awake systolic BP & $10 \mathrm{~mm} \mathrm{Hg}$ & $2.62(2.08-3.32)$ & $<0.0001$ & $0.56(0.50-0.63)$ & $<0.0001$ \\
\hline Awake diastolic BP & $10 \mathrm{~mm} \mathrm{Hg}$ & $1.54(1.22-1.94)$ & $<0.0001$ & $0.64(0.56-0.73)$ & $<0.0001$ \\
\hline
\end{tabular}

Abbreviations: $\mathrm{BP}$, blood pressure; $\mathrm{BMI}$, body mass index; $\mathrm{CV}$, coefficient of variance; F, female; $\mathrm{M}$, male; $\mathrm{MH}$, masked hypertension; OR, odds ratio; WCH, white coat hypertension.

The multivariable models also included a variable for the type of monitor used (Spacelab vs. Accutracker) and an interaction term for the BP monitor and BP variability

Table 3 Clinical predictors of white coat hypertension or white coat uncontrolled hypertension by gender

\begin{tabular}{|c|c|c|c|c|c|}
\hline \multirow[b]{2}{*}{ Predictor } & \multirow[b]{2}{*}{ Unit } & \multicolumn{2}{|c|}{ Men $(\mathrm{n}=1839)$} & \multicolumn{2}{|c|}{ Women $(\mathrm{n}=2110)$} \\
\hline & & OR for $W C H$ & $\mathrm{P}$-value & OR for $\mathrm{WCH}$ & P-value \\
\hline CV (awake systolic BP) & $1 \%$ & $1.02(0.95-1.10)$ & 0.588 & $1.20(1.13-1.28)$ & $<0.0001$ \\
\hline Age & 5 Years & $1.15(1.07-1.25)$ & $<0.0001$ & $1.22(1.14-1.31)$ & $<0.0001$ \\
\hline Treated hypertension & Yes/no & $0.99(0.58-1.68)$ & 0.957 & $0.95(0.65-1.40)$ & 0.804 \\
\hline Treated diabetes & Yes/no & $0.96(0.36-2.58)$ & 0.934 & $1.17(0.58-2.34)$ & 0.660 \\
\hline $\mathrm{BMI}$ & $1 \mathrm{~kg} \mathrm{~m}^{-2}$ & $0.96(0.90-1.01)$ & 0.137 & $1.00(0.96-1.03)$ & 0.828 \\
\hline Awake systolic BP & $10 \mathrm{~mm} \mathrm{Hg}$ & $3.05(1.99-4.64)$ & $<0.0001$ & $2.32(1.74-3.08)$ & $<0.0001$ \\
\hline Awake diastolic BP & $10 \mathrm{~mm} \mathrm{Hg}$ & $1.33(0.90-1.97)$ & 0.154 & $1.72(1.29-2.32)$ & $<0.0001$ \\
\hline
\end{tabular}

Abbreviations: BP, blood pressure; BMI, body mass index; CV, coefficient of variation; OR, odds ratio; WCH, white coat hypertension. The multivariable models also included a variable for the type of monitor used (Spacelab vs. Accutracker).

difference is only a very crude indication of the WCE measured by beat to beat recordings.

The less anticipated variability step-up among patients with isolated ambulatory hypertension ( $\mathrm{MH}$ or masked uncontrolled hypertension) may theoretically stem from a more active lifestyle of these patients, suggested in part by the higher prevalence of younger men and higher awake heart rate. ${ }^{22}$ Alternatively, such as in case of patients with clinic hypertension, highly variable BP may be an inherent characteristic. 
We found that patients with small clinic-aABP difference also had low systolic BP variability (Figure 2). This indicates that regression toward the mean cannot fully account for the relationship between the clinic-aABP difference and systolic BP variability. The positive linear correlation between the clinic-aABP difference and clinic systolic $\mathrm{BP}^{23}$ and the U-shaped relation between $\mathrm{BP}$ variability and the clinic-aABP difference (Figure 1) are actually a different graphic representation (accounting for the absolute clinic-aABP difference) of the same phenomenon. It should be emphasized that, though absolute differences in BP variability between patients with $\mathrm{WCH}$ (or white coat uncontrolled hypertension) and $\mathrm{MH}$ (or masked uncontrolled hypertension) compared with other patients were rather small, comparable differences in variability have been linked to increased cardiovascular mortality. ${ }^{10}$

We also found that higher systolic aABP variability may interfere with accurate BP-related diagnoses based on clinic readings. Patients with highly variable systolic BP have higher odds of being diagnosed with either WCH or MH compared with patients with smaller systolic BP variability. This may mediate the poorer prognosis reported with masked, and to a lesser extent $\mathrm{WCH}$, underlying the importance of ABPM as a tool for the unequivocal diagnosis of hypertension.

Our results show that women with higher awake systolic BP variability are more prone to be misdiagnosed with hypertension compared with men. One explanation for this could be the reported greater prevalence of anxiety among women, ${ }^{2}$ and the more prominent effect of anxiety on BP in women. ${ }^{24}$ Nevertheless, the absent consequence of highly variable BP on the odds of clinic hypertension misdiagnosis in men is surprising and suggests a hypothetic BP lowering effect of the clinic setting in this population. Unlike a recent report, ${ }^{25}$ in which an association was reported between the presence of diabetes and increased BP variability, we found that the adjusted s.d. of awake systolic BP was similar in patients with and without diabetes mellitus, not supporting diabetes as a predictor of $\mathrm{WCH}$ (Table 3). Indeed, previously, ${ }^{26}$ after adjustment for confounders we had found patients with diabetes to have a lesser white coat and a greater masking effect.

Our study is limited in the sense, that clinic BP was taken on a single occasion, not at three separate visits as due, that we used an indirect definition of WCE (based on clinic BP readings taken by a technician) which may underestimate the true $\mathrm{WCE},{ }^{22}$ and its relation to masking effect has not been described. The questionable reproducibility of the clinic-aABP difference is another potential source of inaccuracy. ${ }^{27,28}$ It seems possible that in the case of clinic nonresponders with high systolic BP variability, computation of the clinic-aABP difference based on repeated ABPM would give inconsistent values, providing an explanation for unsatisfactory reproducibility. The referred population of patients, some being treated (with variable ABP control), some untreated, is another limitation, although subgroup analysis by hypertension treatment did not change the results. We did not have data on other parameters known to affect variability such as smoking, menopausal status, obstructive sleep apnea, left ventricular hypertrophy and so on.

The strengths of our study are its size, and a consistent mode of performance that takes into account patients activity report so that no daytime sleep (reported in almost a third) is included in the awake ABP data. Such an inclusion artifactually dampens aABP level and increases its variability. ${ }^{29}$

Our findings indicate that high ambulatory BP variability may hamper accurately diagnosing clinic hypertension based upon a small sample of clinic readings. This is especially important considering the under recognition of $\mathrm{MH}$, which affects about $10 \%$ of the population. ${ }^{1,2,30}$ Thus, a more liberal use of ABPM may be warranted. Further research is necessary to evaluate the causal relationship between greater aABP variability and worse prognosis in patients with masked and WCH.

\section{CONFLICT OF INTEREST}

The authors declare no conflict of interest.

1 Sega R, Cesana G, Milesi C, Grassi G, Zanchetti A, Mancia G. Ambulatory and home blood pressure normality in the elderly. Data from the PAMELA population. Hypertension 1997; 30: 1-6.

2 Ogedegbe G, Pickering TG, Clemow L, Chaplin W, Spruill TM, Albanese GM, Eguchi K, Burg M, Gerin W. The misdiagnosis of hypertension: the role of patient anxiety. Arch Intern Med 2008; 168: 2459-2465.

3 Verberk WJ. Prevalence and persistence of masked hypertension in treated hypertensive patients. Am J Hypertens 2007; 20: 1258-1265.

4 Hansen TW, Li Y, Staessen JA. Blood pressure variability remains an elusive predictor of cardiovascular outcome. Am J Hypertens 2009; 22: 3-4.

5 Veerman DP, de Blok K, van Montfrans A. Relationship of steady state and ambulatory blood pressure variability to left ventricular mass and urinary albumin excretion in essential hypertension. Am J Hypertens 1996; 9: 455-460.

6 Frattola A, Parati G, Cuspidi C, Albini F, Mancia G. Prognostic value of 24-h blood pressure variability. J Hypertens 1993; 11: 1133-1137.

7 Mancia G, Parati G, Hennig M, Flatau B, Omboni S, Glavina F, Costa B, Scherz R, Bond G, Zanchetti A, ELSA Investigators. Relation between blood pressure variability and carotid artery damage in hypertension: baseline data from the European Lacidipine Study on Atherosclerosis (ELSA). J Hypertens 2001; 19: 1981-1989.

8 Sander D, Kukla C, Klingelhöfer J, Winbeck K, Conrad B. Relationship between circadian blood pressure patterns and progression of early carotid atherosclerosis: a 3-year follow-up study. Circulation 2000; 102: 1536-1541.

9 Pringle E, Phillips C, Thijs L, Davidson C, Staessen JA, de Leeuw PW, Jaaskivi M, Nachev C, Parati G, O'Brien ET, Tuomilehto J, Webster J, Bulpitt CJ, Fagard RH, SystEur investigators. Systolic blood pressure variability as a risk factor for stroke and cardiovascular mortality in the elderly hypertensive population. J Hypertens 2003; 21: 2251-2257.

10 Kikuya M, Hozawa A, Ohokubo T, Tsuji I, Michimata M, Matsubara M, Ota M, Nagai K, Araki T, Satoh H, Ito S, Hisamichi S, Imai Y. Prognostic significance of blood pressure and heart rate variabilities: the Ohasama study. Hypertension 2000; 36: 901-906.

11 Verdecchia P, Reboldi GP, Angeli F, Schillaci G, Schwartz JE, Pickering TG, Imai Y, Ohkubo T, Kario K. Short- and long-term incidence of stroke in white-coat hypertension. Hypertension 2005; 45: 203-208.

12 Glen SK, Elliott HL, Curzio JL, Lees KR, Reid JL. White-coat hypertension as a cause of cardiovascular dysfunction. Lancet 1996; 348: 654-657.

13 Cerasola G, Cottone S, Nardi E, D'Ignoto G, Volpe V, Mulé G, Carollo C. White-coat hypertension and cardiovascular risk. J Cardiovasc Risk 1995; 2: 545-549.

14 Mancia G, Bombelli M, Facchetti R, Madotto F, Quarti-Trevano F, Friz HP, Grassi G, Sega R. Long-term risk of sustained hypertension in white-coat or masked hypertension. Hypertension 2009; 54: 226-232.

15 Grin JM, McCabe EJ, White WB. Management of hypertension after ambulatory blood pressure monitoring. Ann Intern Med 1993; 118: 833-837.

16 Ben-Dov IZ, Kark JD, Ben-Ishay D, Mekler J, Ben-Arie L, Bursztyn M. Predictors of allcause mortality in clinical ambulatory monitoring: unique aspects of blood pressure during sleep. Hypertension 2007; 49: 1235-1241.

17 White WB, Lund-Johansen P, Omvik P. Assessment of four ambulatory blood pressure monitors and measurements by clinicians versus intraarterial blood pressure at rest and during exercise. Am J Cardiol 1990; 65: 60-66.

18 White WB, Lund-Johansen P, McCabe EJ, Omvik P. Clinical evaluation of the accutracker II ambulatory blood pressure monitor: assessment of performance in two countries and comparison with sphygmomanometry and intra-arterial blood pressure at rest and during exercise. J Hypertens 1989; 7: 967-975.

19 Owens P, Atkins N, O'Brien E. Diagnosis of white coat hypertension by ambulatory blood pressure monitoring. Hypertension 1999; 34: 267-272.

20 Pickering TG, Hall JE, Appel LJ, Falkner BE, Graves J, Hill MN, Jones DW, Kurtz T, Sheps SG, Roccella EJ. Recommendations for blood pressure measurement in humans and experimental animals: part 1: blood pressure measurement in humans: a statement for professionals from the Subcommittee of Professional and Public Education of the American Heart Association Council on high blood pressure research. Hypertension 2005; 45: 142-161.

21 O'Brien E, Asmar R, Beilin L, Imai Y, Mallion JM, Mancia G, Mengden T, Myers M, Padfield P, Palatini P, Parati G, Pickering T, Redon J, Staessen J, Stergiou G, Verdecchia P. European Society of Hypertension recommendations for conventional, ambulatory and home blood pressure measurement. J Hypertens 2003; 21: 821-848.

22 Ben-Dov IZ, Ben-Arie L, Mekler J, Bursztyn M. In clinical practice, masked hypertension is as common as isolated clinic hypertension: predominance of younger men. Am J Hypertens 2005; 18: 589-593. 
23 Parati G, Ulian L, Santucciu C, Omboni S, Mancia G. Difference between clinic and daytime blood pressure is not a measure of the white coat effect. Hypertension 1998; 31: 1185-1189.

24 James GD, Yee LS, Harshfield GA, Pickering TG. Sex differences in factors affecting the daily variation of blood pressure. Soc Sci Med 1988; 26: 1019-1023.

25 Ozawa M, Tamura K, Iwatsubo K, Matsushita K, Sakai M, Tsurumi-Ikeya Y, Azuma K, Shigenaga A, Okano Y, Masuda S, Wakui H, Ishigami T, Umemura S. Ambulatory blood pressure variability is increased in diabetic hypertensives. Clin Exp Hypertens 2008; 30: 213-224.

26 Ben-Dov IZ, Ben-Ishay D, Mekler J, Ben-Arie L, Bursztyn M. Increased prevalence of masked blood pressure elevations in treated diabetic subjects. Arch Intern Med 2007; 167: 2139-2142.
27 Stenehjem AE, Os I. Reproducibility of blood pressure variability, white-coat effect and dipping pattern in untreated, uncomplicated and newly diagnosed essential hypertension. Blood Press 2004; 13: 214-224.

28 Ben-Dov IZ, Ben-Arie L, Mekler J, Bursztyn M. Reproducibility of white-coat and masked hypertension in ambulatory BP monitoring. Int J Cardiol 2007; 117: 355-359.

29 Bursztyn M, Mekler J, Wachtel N, Ben-Ishay D. Siesta and ambulatory blood pressure monitoring. Comparability of the afternoon nap and night sleep. Am J Hypertens 1994; 7: 217-221.

30 Pickering TG, Gerin W, Schwartz JE, Spruill TM, Davidson KW. Franz Volhard lecture: should doctors still measure blood pressure? The missing patients with masked hypertension. J Hypertens 2008; 26: 2259-2267. 